\title{
Pigment characterisation in Australian rock art: a review of modern instrumental methods of analysis
}

\author{
B. H. Stuart ${ }^{*}$ (iD and P. S. Thomas ${ }^{2}$
}

\begin{abstract}
The many thousands of Aboriginal rock art sites extending across Australia represent an important cultural record. The styles and materials used to produce such art are of great interest to archaeologists and those concerned with the protection of these significant works. Through an analysis of the mineral pigments utilised in Australian rock art, insight into the age of paintings and practices employed by artists can be gained. In recent years, there has been an expansion in the use of modern analytical techniques to investigate rock art pigments and this paper provides a review of the application of such techniques to Australian sites. The types of archaeological information that may be extracted via chemical analysis of specimens collected from or at rock art sites across the country are discussed. A review of the applicability of the techniques used for elemental analysis and structural characterisation of rock art pigments is provided and how future technological developments will influence the discipline is investigated.

Keywords: Rock art, Pigment, Australia, Scanning electron microscopy, X-ray diffraction, X-ray fluorescence spectroscopy, Inductively coupled plasma mass spectrometry, Particle induced X-ray emission spectroscopy, Raman spectroscopy, Infrared spectroscopy
\end{abstract}

\section{Background}

The rock art that exists in many parts of the world reflects human behaviour, relationships and experiences and can date back to prehistoric times. The oldest continuous tradition of rock art in the world exists in Australia and this provides an important component of the culture of Aboriginal Australia. Rock art sites exist is many parts of the country, with a high concentration spectacular rock art sites located in the tropical north of the country from Western Australia across to northern Queensland. Australian rock art is represented by many different artistic styles and techniques, often reflecting artistic practices during particular time periods. As such, Australian rock art is of great archaeological interest.

The focus of scientific studies of Australian rock art has been the dating of carbon-based material found at sites of

\footnotetext{
*Correspondence: barbara.stuart@uts.edu.au

${ }^{1}$ Centre for Forensic Science, University of Technology Sydney, 15 Broadway, Ultimo, NSW 2007, Australia

Full list of author information is available at the end of the article
}

interest [1-4]. Since the mid-1980s, radiocarbon dating of rock art using accelerator mass spectrometry (AMS) has been used to directly date rock paintings. Carbon isotope analysis can be carried out on charcoal pigments, as well as the organic constituents of paint residues or inclusions in mineral accretions. Suitable organic material is not always available or in an appreciable quantity to allow a reliable analysis. However, there is also potential information to be obtained about pigment sources and history from the inorganic material (e.g. mineral pigments) used in traditional paint to broaden the analytical information obtained from rock art.

In addition to chronological information, the analysis of rock art pigments can provide insight into production methods, a link between a painting and a source. Different methods of paint production are employed in different regions and by different groups. Mixing with extenders (e.g. ochre with kaolinite), the use of binders (e.g. plant resins, wax) and/or heat treatment to alter the colour of a pigment can be determined via pigment analysis. A link between the composition of paint and a 
source material (e.g. a local ochre mine) has the potential provide valuable archaeological information. Additionally, a connection between archaeological fragments and rock art can be facilitated by the cross-correlation of the chemical and physical properties. The analysis of the pigments contained in superimposed images (an example painting is illustrated in Fig. 1) provides details about the relative age of particular paintings and also when and if pigment use has changed over time. The identification of conversion products that result from weathering processes of pigments can also provide supporting information about age and preservation.

Ochre is an important component of paint used in traditional, as well as modern, Australian indigenous art. The source material was extensively traded across Australia in the past and it has been established that the chemical composition of ochres is dependent on the source $[5,6]$. Ochre is a mixture of natural minerals including iron oxide and clays [7]. Iron oxides, including haematite $\left[\mathrm{Fe}_{2} \mathrm{O}_{3}\right]$ and goethite $[\mathrm{FeOOH}]$, in their different forms and combined with other minerals are responsible for the characteristic red, yellow and orange colours associated with this pigment source. Kaolinite $\left[\mathrm{Al}_{2} \mathrm{Si}_{2} \mathrm{O}_{5}(\mathrm{OH})_{4}\right]$, huntite $\left[\mathrm{CaMg}_{3}\left(\mathrm{CO}_{3}\right)_{4}\right]$, gypsum $\left[\mathrm{CaSO}_{4} \cdot 2 \mathrm{H}_{2} \mathrm{O}\right]$ and/or calcite $\left[\mathrm{CaCO}_{3}\right]$, for example, are minerals present in Australian white pigments. The specific compositions of such minerals vary by source location. Black pigments have been widely produced from charcoal, but mineral pigments such as manganese dioxide can be the source of this colour in certain parts of Australia. As there is not generally a history of chemical or thermal modification of pigments in Aboriginal art, the variation in elemental composition and morphology resulting from different geological formations of ochre has the potential to be linked to a source.

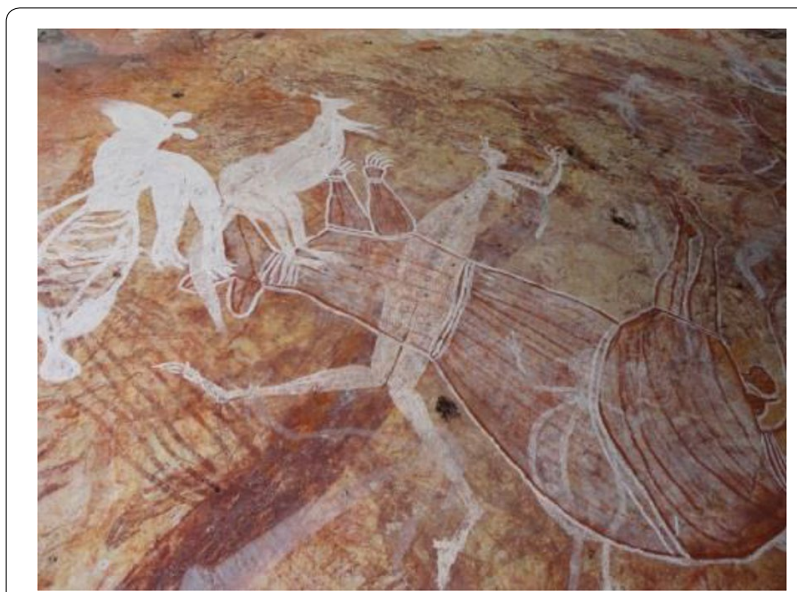

Fig. 1 Superimposed rock art images, Dalakngalarr 1 rockshelter in Arhnem Land, Northern Territory. (Photograph by Barbara Stuart)
The transformation of particular minerals as a result of environmental exposure may also provide insight into the history of particular rock art. The oxalates, whewellite $\left[\mathrm{Ca}\left(\mathrm{C}_{2} \mathrm{O}_{4}\right) \cdot \mathrm{H}_{2} \mathrm{O}\right]$ and weddelite $\left[\mathrm{Ca}\left(\mathrm{C}_{2} \mathrm{O}_{4}\right) \cdot 2 \mathrm{H}_{2} \mathrm{O}\right]$, form deposits on rock surfaces $[8,9]$. The oxalates may be produced by the reaction of calcite with oxalic acids formed by microorganisms including algae, fungi and lichens or is formed from bat guano, which contains ammonium oxalate. When the $\mathrm{Ca}^{2+}$ ion diffuses into oxalate-rich environment, the monohydrate whewellite is formed, while the dihydrate weddelite is formed when the $\mathrm{C}_{2} \mathrm{O}_{4}^{2-}$ ion diffuses into a calcium-rich environment. Any weddelite that does form eventually transforms into whewellite in the presence of water as the latter is the more thermodynamically stable form. The oxalate minerals in white paint are believed to be a result of the microbiological alteration of huntite and calcite [10]. The oxalate materials that cover (or lie beneath) rock art have proven to be a source of information about when a painting was produced (e.g. [9]).

The analysis of rock art pigments does usually involve a combination of analytical techniques to provide a comprehensive characterisation of the pigment chemistry at a site: the pigments used are often complex mixtures and one single approach does not usually provide all the information required. Elemental analysis is an established approach, especially given its widespread use in mineralogical studies. Scanning electron microscopy combined with energy dispersive X-ray analysis (SEM-EDX) can provide morphological information regarding minerals in conjunction with a semi-quantitative elemental profile [11]. X-ray fluorescence (XRF) spectroscopy allows an elemental profile of a pigment to be obtained and has expanded in application to rock art studies in recent years with the development of portable instrumentation. Such equipment allows in situ examination of rock sites, thus minimising damage associated with the collection of analytical specimens [12]. Related to XRF is electron microprobe analysis (EMPA), but this technique is less widely available than XRF due to lack of portability and cost and has had limited use in recent rock art studies. Inductively coupled plasma-mass spectrometry (ICPMS) has emerged as a popular technique for elemental analysis, including its application to paint, due to its enhanced sensitivity. Although conventional ICPMS is destructive by nature, laser ablation (LA) ICPMS involves the removal of a small quantity of solid surface material (micron size) and is regarded as semi-quantitative as the sample properties can influence the amount of material ablated [13]. Particle induced X-ray emission (PIXE) and proton induced gamma emission (PIGE) spectroscopies are non-destructive techniques than can provide quantitative information about heavier elements $[11,14]$. 
However, PIXE/PIGE require access to an accelerator, which limits access compared to XRF for rock art pigment characterisation.

Techniques that are able to provide a more direct structural identification of the mineral content of rock art are increasingly being used in partnership with elemental analysis. Quantitative mineral analysis is provided by $\mathrm{X}$-ray diffraction (XRD) methods, which, for instance, can be used to differentiate the various forms of iron oxide (e.g. haematite, goethite). The amount of specimen required in conventional XRD has limited its application, but where synchrotron XRD is available, much smaller specimens can be successfully examined [15]. For the identification and characterisation of pigment minerals, Raman and infrared spectroscopies may also be applied $[11,16]$. Microscopic sampling accessories enable very small specimens and paint layers to be investigated.

With the increased sensitivity, portability and costeffectiveness of modern analytical techniques, their use for rock art analysis has expanded in recent years. This paper provides a review of recent studies where analytical techniques have been applied to pigments from rock art sites located in different regions of Australia. An examination of how such techniques provide insight into the different archaeological and cultural questions arising from sites across the country are addressed in this review.

\section{Rock art site pigment analysis in Western Australia}

Numerous and renowned rock art sites are located in Western Australia, particularly in the Kimberley region in the north. In an early examination of rock art sites in the Napier Range in the Kimberley region of Western Australia, Ford et al. [10] focused on the identification of white hued pigments that dominate the palette in this area. Their SEM-EDX and XRD examinations revealed that the major mineral components of the pigments were huntite, whewellite, calcite and dolomite. The widespread occurrence of whewellite lead the authors to conclude that oxalate ions (produced by microorganisms and/or weather events at this site) reacted with huntite or calcite to produce the oxalate.

SEM-EDX analyses have been carried out to understand the source of the distinctive mulberry pigments that are widespread in Kimberley rock art [17]. Where this notable colour had previously been believed to have such as blood, been produced by the addition of an organic substance in the binding medium, the elemental analysis was able to demonstrate that the colour was, in fact, associated with the presence of the mineral jarosite $\left[\mathrm{KFe}_{3}^{3+}(\mathrm{OH})_{6}\left(\mathrm{SO}_{4}\right)_{2}\right]$ which forms as a weathering product to produce mineralised veins within rocks located in the tropical climate of the Kimberley region $[10,18]$. A more recent analytical approach has been undertaken to understand the composition of the mulberry coloured paintings [18]. Through the use of portable XRF, XRD and SEM-EDX, the composition of haematite (Fe with lower $\mathrm{K}$ and $\mathrm{S}$ ) and jarosite (Fe with higher $\mathrm{K}$ and $\mathrm{S}$ ) were identified as a means of differentiating pigments.

The identification of minerals in very small (approximately $3 \mu \mathrm{g}$ ) stratified rock art paint specimens from the Kimberley region has been investigated using synchrotron XRD [15]. Such layering of a Wandjina painting was first presented by Clarke [19]. The examination of a specimen collected from a Wandjina motif in a rockshelter in the central Kimberley demonstrated that the mineral identification of individual paint layers is possible using the synchrotron technique, compared to a traditional powder XRD technique that requires larger quantities of material to obtain effective data to successfully characterise the mineral compositions.

One of the first reported detailed analysis of Australian ochre pigments was carried out by Clarke [19]. Techniques, including XRD and EPMA, were used and samples collected from the Wilgie Mia ochre mine in the Mid West region of Western Australia were investigated. Scadding et al. [13] has more recently demonstrated the potential of LA-ICPMS as a technique for the grouping of ochres from the same locality. The technique was used to compare the elemental compositions of red and yellow ochres collected from the Wilgie Mia and Littile Wilgie ochre mines with those used at the rock art sites. By using a LA-ICPMS analysis of the 59 isotopes present, the trace element chemistry of the ochre quarries only $3 \mathrm{~km}$ apart could be discriminated. The analysis was able to propose that the Little Wilgie mine site was the more likely source of ochre used for the production of rock art at nearby rockshelter sites.

\section{Rock art site pigment analysis in the Northern Territory}

Arnhem Land in the Northern Territory is home to one of the world's greatest collections of rock art with paintings dating back tens of thousands of years [20]. In 2007, a large number of remote rock shelters were rediscovered on the Arnhem Land plateau located in the Northern Territory [21]. Questions exist about the origins and the preparation methods used for the pigments in the multitude of paintings. Understanding pigments has been the subject of recent on-going studies. Amongst the many decorated shelters in this region is Dalakngalarr 1, containing more than 500 images believed to have been produced over an extensive time period [22]. The sites contain many 'X-ray' style paintings, where the internal organs and bones of animals are represented (an example is illustrated in Fig. 2). The pigments employed in X-ray paintings at this site have been the subject of a recent 


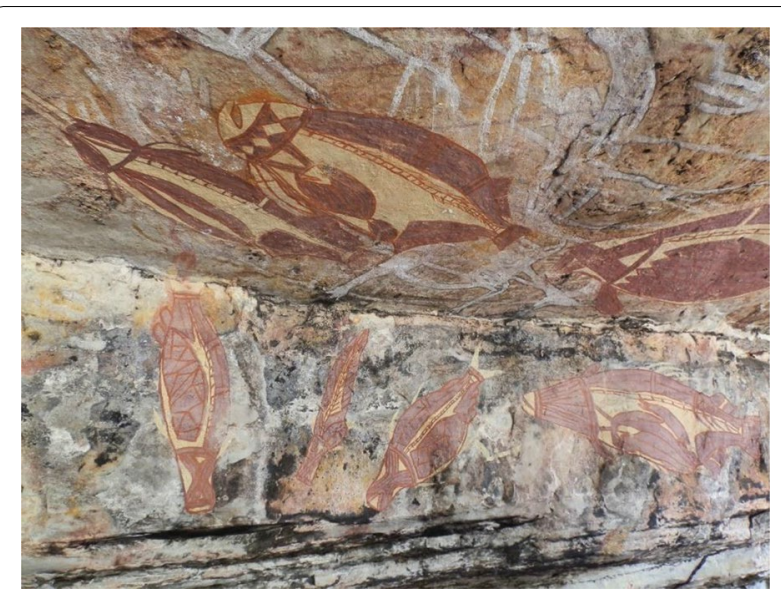

Fig. 2 X-ray style rock art images, Dalakngalarr 1 rockshelter in Arhnem Land, Northern Territory. (Photograph by Paul Thomas)

study by Hunt and co-workers [23]. The focus of the investigation was to understand the source of an unusual purple pigment observed in X-ray art at the Dalakngalarr 1 site. Infrared and Raman spectroscopies, along with SEM-EDS, were employed to gain insight into the nature of the unusually coloured pigment. The use of the spectroscopic techniques enabled haematite and kaolinite to be identified as present in both the red and purple pigments used in specific X-ray paintings at the site. Additionally, insight into differences in the mineral crystalline structure and particle size was gained using these techniques with a pure form of haematite identified in the purple pigment that differentiated its structure from that of the red pigment used in the same paintings.

Another significant rockshelter on the Arnhem Land plateau is the 'Genyornis' site, so named because of the presence of a painting of a large bird resembling the extinct Genyornis newtoni species. The site has been the subject of a recent comprehensive report that included the characterisation of pigments used in painted panels with SEM-EDX, PIXE and Raman spectroscopy being employed [24]. Haematite was identified as a principal component of red pigments, while goethite was found to form the yellow pigments at the site. However, additional compounds, including oxalate and leucophosphite, were identified and provided information about weathering processes of the substrate. The authors of this study were able to examine cross-sections of paint specimens collected from the site and microstratigraphic analysis enabled the sequence of overlapping paintings to be clarified. A visual examination of the paintings had previously lead investigators to believe that a faint anthropomorph figure was superimposed over a large bird motif with a spear image, but microstratigraphic analysis demonstrated that the anthropomorph was, in fact, painted first with the 'Genyornis' bird and spear later painted together on top.

The use of portable XRF as a non-destructive field technique has been investigated in a study of rock art located at the Urrmarning site in western Arnhem Land [25]. The significant finding was a high concentration of lead in a black painted motif, indicating that black pigments obtained from local mineral sources could be eliminated based on the elemental composition-charcoal and manganese oxide have been previously observed in western Arnhem Land rock art. Processed metal lead was proposed as the likely source. Despite the age of the painting employing this pigment being stylistically suggested to be old in age, the presence of lead in the black pigment implies that the age is much more recent, painted within the last couple of centuries and associated with European contact.

As part of a dating study of rock art in the Victoria River District of the Northern Territory (lying between the Arnhem Land and Kimberley regions), the compositions of different paint colours have been determined using XRD [26]. The white pigments were found to consist mainly of huntite, gypsum and the oxalates whewellite and weddelite. The conversion, or not, of huntite into oxalates enables variation in mineral composition of pigment specimens to be identified. Such variation may potentially be employed to link white pigments to local sources or to determine if the pigments have been obtained as a result of trade with the Kimberley region of Western Australia.

\section{Rock art site pigment analysis in Queensland}

North Queensland is home to some of Australia's most well-known rock art regions, with art dating back many thousands of years [27]. Paint composition analysis has been reported in several studies of rock art sites in the Laura district within Quinkan country in northern Queensland [28-30]. Certain rock art in the region depicts figures associated with nineteenth century colonial conflict and has provided insight into the artists' practices during that period. Compositions of the mineral content, determined using SEM-EDX and XRD, of a range of figures helped explain the differing choices of pigment used by the artists. The pigments standardly used and obtained from local sources were characterised (e.g. kaolinite for white, haematite and quartz for red). Interestingly, the determination of pigment compositions used in the contact paintings that varied from the traditional sources revealed the choice of rare or high grade pigments. Their use appears indicate a search for new pigments to incorporate colours not previously represented in Australian rock art (e.g. grey paint to represent a blue trooper's shirt from the colonial period). 
In their study of hand stencils at a site in North Queensland, Goodall and co-workers [31] have demonstrated that it is possible to obtain chronological information about rock art even when there is insufficient carbon material available to carry out radiocarbon dating. In this study, a combination of Raman and infrared microspectroscopies with SEM-EDX were utilised to examine cross-section layers used in wall paintings at Fern Cave. In this limestone cave, gypsum was proposed to be formed as an evaporative layer during arid conditions and may be used to determine whether different paintings in the cave were above or below gypsum layers formed during the most recent purported dry phase 4000 years ago.

\section{Rock art site pigment analysis in New South Wales}

An early mineralogical survey of rock art sites in western New South Wales was carried out to instigate procedures for the conservation of such sites [32]. This study included an early application of infrared spectroscopy, $\mathrm{XRD}$ and XRF analyses to identify the main components of the yellow, red, black and white pigments collected. Although the technology of the time limits the sensitivity of the results, the useful nature of such techniques was demonstrated.

Much of the pigment analysis work carried out in New South Wales has been performed on rock art sites located in the Sydney Basin area. Huntley et al. [33] carried out a pilot pigment characterisation study of sites on the Woronora Plateau. SEM-EDX, XRD and PIXE/PIGE were used to examine white yellow, red, black and orange specimens collected from various motifs. Combinations of iron oxide, charcoal and weathered local sandstone dispersed in a clay base were found to be the compositions used. The results of the study also confirmed that paints were used i.e. pigments in liquids applied wet to the rock. An examination of the morphology of the paints supported the theory that the paint was applied via the mouth of the artist Thus, the study provided insight into how the pigments were prepared and applied, in addition to a knowledge of the local paint components.

Huntley followed up the study of rock art from the Sydney Basin with several projects to test the applicability of portable XRF spectroscopy [12, 34]. The XRF data gathered confirmed that locally sourced composite claybased pigments were used in this region. Multivariate analysis, including principal component analysis (PCA) and hierarchical cluster analysis (HCA), were used to link the paint components with the composition of their local sources. Huntley discussed how the physical properties of rock art paints influence the portable XRF spectroscopy results. Microstructural properties, such as grain size and porosity, have the ability to attenuate the $\mathrm{X}$-ray signals and, as a consequence, influence a quantitative elemental analysis of rock art. The analyses also enabled the first confirmation of the use of a high quality calcite matrix ochre in Sydney Basin archaeological assemblages.

\section{Rock art site pigment analysis in South Australia}

There are fewer reported analytical studies of rock art sites in South Australia, although there has been a number of reports regarding ochre chemistry from this part of the country $[5,6]$. However, a multi-analytical approach has been applied to an investigation of a rock coating in a complex located in South Australia [8]. A dark film on the rockshelter at Ngaut Ngaut was studied using techniques including XRD, SEM, Raman spectroscopy and infrared spectroscopy to understand the origin of the film. An effective technique for this particular project was XRD, which was used to confirm the presence of weddelite in the rock coating. SEM was used to image the morphological form of the mineral. The authors were not able to obtain definitive mineral identification based on the infrared spectra obtained and the issue of fluorescence in the Raman spectra limited the applicability of this technique. The presence of weddelite at this site was the first report of the mineral at a rock art site in South Australia, providing a potential source of a dating material.

\section{Conclusions}

An overview of the characterisation of rock art pigments in locations across Australia has been provided in this paper and has demonstrated the expanding use of modern analytical techniques to the many archaeological and heritage questions that arise from such important sites. Through the successful identification of the chemical composition of complex pigment mixtures questions about the source of materials and how and when they were applied can be answered. Specifically, links to material sources (local or traded), the origins of special colours, preparation methods and method of application, the sequencing of painting from stratified paint layers, and the weathering processes to age works have been investigated via a chemical characteristion of rock art materials.

One of the major challenges with the analysis of rock art is to minimise damage to a site and to avoid the need to remove specimens for laboratory analysis. The recent use of synchrotron techniques (XRD and infrared spectroscopy) has been helpful on this front as high quality information from very small fragments of Australian rock art has been obtained. High resolution mineralogical information will help clarify whether rock art paint compositions are associated with the artists' choice of pigment or are due to post-depositional processes occurring within the paint. The use of portable XRF, Raman 
and infrared spectrometers is expanding in other disciplines, such as forensic science and mineralogy. At the same time, the sensitivity and the quality of data collected using portable instruments for field work has significantly improved. The in situ use of such instruments at rock art sites will allow a clearer understanding of the complex chemistry that exists in rock art and will add to the conservation and archaeological picture of such special sites.

\section{Authors' contributions}

BS and PT wrote the manuscript. Both authors read and approved the final manuscript.

\section{Author details \\ ${ }^{1}$ Centre for Forensic Science, University of Technology Sydney, 15 Broadway, Ultimo, NSW 2007, Australia. ${ }^{2}$ School of Mathematical and Physical Sciences,} University of Technology Sydney, 15 Broadway, Ultimo, NSW 2007, Australia.

\section{Acknowledgements}

The authors acknowledge Margaret Katherine and the Jawoyn Association for their kind permission to collect photographs and collect specimens at Dalakngalarr 1, and to A/Prof. Bruno David of Monash University for allowing us to collaborate on the project.

\section{Competing interests}

The authors declare that they have no competing interests.

Received: 21 December 2016 Accepted: 18 February 2017

Published online: 13 March 2017

\section{References}

1. Bednarik RG. Rock art. In: Pearsall DM, editor. Encyclopedia of archaeology. Amsterdam: Elsevier; 2008. p. 1940-52.

2. David B, Geneste JM, Petchey F, Delannoy JJ, Barker B, Eccleston M. How old are Australia's pictographs? A review of rock art dating. J Arch Sci. 2013:40:3-10.

3. Langley MC, Taçon PSC. The age of Australia rock art: a review. Aust Archaeol. 2010;71:70-3.

4. Aubert M. A review of rock art dating in the Kimberley, Western Australia. J Arch Sci. 2012;39:573-7.

5. Creagh DC, Kubik ME, Sterns M. One the feasibility of establishing the provenance of Australian Aboriginal artefacts using synchrotron radiation X-ray diffraction and proton induced X-ray emission. Nucl Instrum Methods Phys Res A. 2007;580:721-4.

6. Popelka-Filcoff RS, Lenehan CE, Lombi E, Donner E, Howard DL, de Jonge MD, Paterson D, Walshe K, Pringad A. Microelemental characterisation of Aboriginal Australian natural Fe oxide pigments. Anal Methods. 2015;7:7363-80

7. Eastaugh N, Walsh V, Chaplin T, Siddall R. Pigment compendium. Abingdon: Butterworth-Heinemann; 2004

8. Roberts AL, Campbell I, Pring A, Bell G, Watchman AL, Popelka-Filcoff RS, Lenehan CE, Gibson CT, Franklin N. A multidisciplinary investigation of a rock coating at Ngaut Ngaut (Devon Downs), South Australia. Aust Archaeol. 2015:80:32-9.

9. Watchman A, O'Connor S, Jones R. Dating oxalate minerals 20-45 ka. J Arch Sci. 2005:32:369-74.

10. Ford B, Macleod I, Haydock P. Rock art pigments from the Kimberley region of Western Australia: identification of the minerals and conversion mechanisms. Stud Conserv. 1994;39:57-69.

11. Rowe M. Physical and chemical analysis. In: Whitley D, editor. Handbook of rock art research. Lanham: Altamira Press; 2001. p. 190-220.

12. Huntley J. Taphonomy or paint recipe: in situ portable $\mathrm{x}$-ray fluorescence analysis of two anthropomorphic motifs from the Woronora Plateau, New South Wales. Aust Archaeol. 2012;75:78-94.
13. Scadding R, Winton V, Brown V. A LA-ICP-MS trace element classification of ochres in the Weld Range environ, Mid West region, Western Australia. J Arch Sci. 2015;54:300-12.

14. Nel P, Lynch P, Laird JS, Casey HM, Goodall LJ, Ryan CG, Sloggett RJ. Elemental and mineralogical study of earth-based pigments using particle induced X-ray emission and X-ray diffraction. Nucl Instrum Meth A. 2010;619:306-10.

15. Huntley J, Brand H, Aubert M, Morwood MJ. The first Australian Synchrotron powder diffraction analysis of pigment from a Wandjina motif in the Kimberley, Western Australia. Aust Archaeol. 2014;78:33-8.

16. Bersani D, Lottici PP. Raman spectroscopy of minerals and mineral pigments in archaeometry. J Raman Spectrosc. 2016;47:499-530.

17. Ward I, Watchman A, Cole N, Morwood M. Identification of minerals in pigments from aboriginal rock art in the Laura and Kimberley regions, Australia. Rock Art Res. 2001;18:15-23.

18. Huntley J, Aubert M, Ross J, Brand HEA, Morwood MJ. One colour, (at least) two minerals: a study of mulberry rock art pigment and a mulberry pigment 'quarry' from the Kimberley, Northern Australia. Archaeometry. 2015;57:77-99.

19. Clarke J. Two Aboriginal rock art pigments from Western Australia: their properties, use, and durability. Stud Conserv. 1976;3:134-42.

20. Chaloupka G. Journey in time: the world's longest continuing art tradition. Chatswood: Reed; 1993.

21. Gunn RG, Whear RL. The Jawoyn rock art and heritage project. Rock Art Res. 2007;24:5-20.

22. James D, David B, Delannoy J-J, Gunn RG, Hunt A, Moffat I, lacono N, Stephens S-P. Archaeology of rock art at Dalakngalarr 1, central-western Arnhem Land. In: David B, Taçon PSC, Delannoy J-J, Geneste J-M, editors. Terra Australis: The archaeology of rock art in Western Arnhem Land, Northern Australia. Canberra: ANU Press; 2017

23. Hunt A, Thomas PS, James D, David B, Geneste JM, Delannoy JJ, Stuart BH. The characterisation of pigments used in X-ray rock art at Dalakngalarr 1, central-western Arnhem Land. Microchem J. 2016:126:524-9.

24. Chalmin E, Castets G, Delannoy JJ, David B, Barker B, Lamb L, Soufi F, Pairis S, Cersoy S, Martinetto P, Geneste JM, Hoerle S, Richards T, Gunn R. Geochemical analysis of the painted panels at the 'Genyornis' rock art site, Arnhem Land, Australia. Quat Int. 2016. doi:10.1016/j.quaint.2016.04.003.

25. Wesley D, Jones T, Reepmeyer C. Pigment geochemistry as chronological marker: the case of lead pigment in rock art in the Urrmarning'Red Lily Lagoon' rock art precinct, western Arnhem Land. Aust Archaeol. 2014;78:1-9.

26. Watchman A, Flood J, Chippendale C. Dating of rock images in Wardaman Country, Northern Territory, Australia. Rock Art Res. 2004;21:173-82.

27. Cole N. Rock art in the Laura Cooktown region. In: Morwood M, Hobbs D, editors. Quinkan prehistory: the archaeology of Aboriginal art in SE Cape York Peninsula, Australia. St Lucia: University of Queensland; 1995. p. $51-70$.

28. Watchman A, Sirois J, Cole N. Mineralogical examination of Aboriginal rock painting pigments near Laura, North Queensland. In: Fankhauser BL, Bird JR, editors. Archaeometry: occasional papers in prehistory. Canberra: Australian National University; 1993. p. 141-50.

29. Cole N. Rock paintings are stories: rock art and ethnography in the Laura region, Cape York Peninsula. Rock Art Res. 2011;28:107-16.

30. Cole N. Painting the police: aboriginal visual culture and identity in colonial Cape York Peninsula. Aust Archaeol. 2010:71:17-28.

31. Goodall RA, David B, Kershaw P, Fredericks PM. Prehistoric hand stencils at Fern Cave, North Queensland (Australia): environmental and chronological implications of Raman spectroscopy and FT-IR imaging results. J Arch Sci. 2009;36:2617-24.

32. Walston S, Dolanski J. Two painted and engraved sandstone sites in Australia. Stud Conserv. 1976;21:1-17.

33. Huntley J, Watchman A, Dibden J. Characteristics of a pigment art sequence: Woronora Plateau, New South Wales. Rock Art Res. 2011;28:85-97.

34. Huntley J. Looking up and looking down: pigment chemistry as a chronological marker in the Sydney Basin rock art assemblage, Australia. Rock Art Res. 2015;32:131-45. 